\title{
ESTUDIOS
}

\section{Martí en las Revistas del Modernismo Antes de su Muerte*}

\begin{abstract}
Abundan comentarios encaminados a destacar la originalidad de M:artí como escritor, como pensador, como orador, como poeta, así como otros que lo ensalzan como luchador por la libertad, como idealista portavoz de lo mejor de Nuestra América, como amigo, como hombre completo.

El escritor chileno Pedro Pablo Figueroa caracterizó a José Martí, en 1891, como "uno de los más brillantes ingenios de la América contemporánea que en la prensa ejerce profunda influencia sobre los espíritus mejor cultivados, con los fulgores de su estilo y de su pluma. José Martí es un escritor de universal originalidad... Sus escritos atraen la atención pública con el brillo, novedad y la elocuencia de su forma, la belleza de sus períodos, la elegancia y espiritualidad de sus conceptos y la sutileza de su filosofía..." 1

Al leer los escritos de Martí reproducidos de La Nación por el Mer-

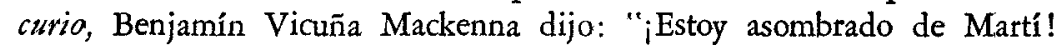
¡Qué modo de concebir y expresar sus ideas! Maneja la pluma como Gustavo Doré jugaba con el lápiz".22

El mismo Figueroa cita al uruguayo Alejandro Magariños Cervantes, al colombiano Miguel Antonio Caro, al mexicano Juan de Dios Peza y

* Trabajo leído en Denver, Colorado, en la reunión anual de la Modern Language Association, el 28 de diciembre de 1969.

i "José Martí (El Castelar Americano)" Revista Cubana (Homenaje a José Martí en el Centenario de su nacimiento), XXIX (julio 1951-diciembre 1952), p. 180. Al final de este artículo leemos: Santiago de Chile, junio 16 de 1891 . Edición Gonzalo de Quesada, vol. VIII.

2.Ibid., p. 184 .
\end{abstract}


a otros en lo referente a lo nuevo y a la originalidad del pensamiento y del estilo del apóstol. ${ }^{3}$

Eduardo de la Bara afirma que José Martí es "el más eminente y brillante prosador de cuantos" " conoce. Bartolomé Mitre lo califica de "escritor original y pensador americano".5 En el artículo que Rubén Darío dedicó al maestro a raíz de su muerte, artículo que apareció en Los Raros el año siguiente, observa que la cultura de Martí "era proverbial, su honra intacta y cristalina; quien se acercó a él se retiró queriéndole. Y era poeta y hacia versos". ${ }^{\text {" }}$ "Nunca la lengua nuestra tuvo mejores tintas, caprichos y bizartías".

Hay que notar, sin embargo, que con anterioridad a su muerte - que sepa you no se calificó a Martí de modernista. Pedro Pablo Figuetoa se acerca a este concepto de la originalidad martiana al afirmar, en 1891, que Martí "pertenece, por el estilo, a la escuela moderna de los prosistas poetas, que hacen del lenguaje la poesía del arte de la expresión".

El nombre de Martí no se encuentra con los de Verlaine, Baudelaire, Huysmans, Dario, Casal, Ambrogi, José Antonio Román, José Fiansón, Chocano, Abraham 'Z. López Penha, en el artículo de Clemente Palma sobre "La decadencia en América" que se publicó en El Iris correspondiente al mes de julio de 1894. Tampoco se halla con los de Catulle Mendés, Leconte de Lisle, Rubén Darío, Francisco Gavidia, Justo A. Facio, Julián del Casal, Domingo Martínez Luján y otros escritores de la misma tendencia, en el ensayo de Remigio Crespo Toral (pseud. Stein) sobre "Los parnasianos en América", publicado en el número de La Unión Literaria (revista ecuatoriana) correspondiente al mes de marzo de 1894.

"En los poetas modernistas no hay directamente admiración por Mas. tí poeta, ni contacto directo y visible con Martí", observa Andrés Iduarte en Martí escritor (1945). Y agrega: "Nos parece que el modernismo como escuela subestimó a Martí o lo vio como cosa ajena y distante". 9

Veamos ahora qué pruebas se pueden aducir en apoyo de esta opinión, dando respuesta a las preguntas siguientes:

3 Ibid.., pp. 184-185.

"Véase: Enrique Trujillo, "José Marti", Revista Cubana, XXIX (jul. 1951. dic. 1952), p. 200. (Ed. Gonzalo de Quesada, XIX).

5 Ibid.

6 Obras completas, II, Madrid, Afrodisio Aguado, 1950, p. 487.

7 Ibid., p. 481.

8 Op. cit., p. 182.

9 Andrés Iduarte, Martí escritor. México: Ediciones Cuadernos Americanos, 1945 , p. 360. 
¿Qué escritos de Martí aparecieron en las revistas del Modernișmo publicadas durante 1894 y 1895 ?

¿Cómo aparecen Martí y su obra en aquellas revistas?

¿Qué eco tuvo la muerte del héroe en dichas revistas?

A continuación, en orden cronológico ${ }^{10}$ de aparición durante el año 1894, se dan los títulos de las revistas estudiadas para los fines de esta investigación: El Renacimiento 2a. serie (México; 1894); Cosmópolis (Venezuela; 1894-1895); Revista Azul (México; 1894-1896); El Iris (Perú; 1894); Revista Blanca (Cuba; 1894-1896); Revista de América (Argentina; 1894); El Mundo (México; 1894-1914). Además de éstas, El Cojo Ilustrado (Venezuela; 1892-1915), prestigiada revista fundada en 1892; el Primer Almandque Mexicano de Arte y Letras (1895), y el Segundo del mismo título en 1896; Revista Nacional de Literatura y Ciencias Sociales (Uruguay; 1895-1897).

He aquí otras revistas, vehículos del Modernismo en 1894, que no me fue dado examinar para los propósitos de este estudio: Revista Gris (1893-1894) y Revista Literaria (1890-1894) de Colombia; La Pluma (1893-1894), El Pensamiento (1894-1896) y La Juventud Salvadoreña (1889-1897) de El Salvador. Con respecto a estas publicaciones, conviene observar que el nombre de Martí no se halla entre los autores que menciona John E. Englekirk en las notas que dedica a dichas revistas ${ }^{11}$ en La literatura y la revista literaria en Hispanoamérica. Tampoco figura Martí en el Indice ${ }^{12}$ de la Revista Cómica (1895-1896) de Chile por John M. Fein.

Martí hizo su tercero y último viaje a México en 1894. Llegó hacia el 18 de julio y permaneció allí hasta el 10 de agosto. Fue un viaje de paso inspirado en esperanzas que resultaton vanas, de poder conseguir el apoyo de México a favor de la revolución cubana. Si fracasó respecto a su objetivo político, tuvo éxito en lo tocante al aspecto personal de su visita. Renovó viejas amistades, entre ellas la de Manuel A. Mercado

10 El Renacimiento, 2a. serie (enero 14-junio 24, 1894, nos. 1-24, 403 pp.); Cosmópolis (lo. de mayo de 1894-julio de 1895, nos. 1-12); Revista Azul (6 de mayo de 1894-11 de octubre de 1896, I-V); El Iris (1o. de junio a octubre de 1894, nos. 1-5); Revista Blanca (15 de julio de 1894-noviembre de 1896, nos. 1-24 - directora Luz Guy); Revista de América (19 de agosto, 5 de septiembre, lo. de octubre de 1894, nos. 1-3); El Mundo - El Mundo Ilustrado a partir de 1900 - (nov. 4 de 1894 - 1914, I-XXI).

${ }_{11}$ Véase: Revista Iberoamericana (XXVI, No. 51, pp. 44-45) para las notas del profesor Englekirk sobre las revistas Colombia Ilustrada y Revista Gris; $\theta$ ibid. (XXVIII, no. 53, pp. 41-42) para las del mismo autor sobre La Juventud Salvadoreña, La Pluma y el Pensamiento.

12 John M. Fein, Modernismo in Chilean Literature. The Second Period. Durham, N.C.: Duke University Press, 1965, pp. 135-147. Allí se hallan los nombres de Darío, Ambrogi, Lugones, Salvador Rueda, Brenes Mesén y otros modernistas. 
y contrajo otras nuevas, incluso la de Manuel Gutiérrez Nájera. Aun cuando en las cartas ${ }^{13}$ de Martí a Mercado, amigo mutuo éste de ambos poetas, se hallan frecuentes referencias a El Duque Job a partir de 1888, no parece que se conocieran personalmente antes de 1894.

Que la presencia de Martí en la capital tuvo notable eco ${ }^{14}$ en los círculos literarios, lo atestiguan los recuerdos de varios escritores de aquel tiempo, entre ellos los de Urbina, Nervo, Díaz Dufóo y Gutiérrez Nájera.

Leemos en El Universal (22 de julio de 1894): "Ha pasado rápidamente -tal vez a la bora en que estas lineas aparezcan babna ya partido- por México un gran artista, un excelso tribuno, un poeta centelleante, un magno espíritu: José Martí. Aquí dejó hace 17 años robustas amistades y altas admiraciones que han crecido. Esta es su tierra, porque él no es de Cuba nada más: es de América". Cuando José de J. Níñez y Domínguez recopiló este comentario en su Martí en México (p. 82) omitió las palabras en letra bastardilla. Además, no sabía al parecer, que el autor del comentario era Manuel Gutiérrez Nájera.

Por casualidad descubrí la identidad del autor de la nota en cuestión leyendo un artículo de César Zumeta, "Un 'suelto' de crớnica", en la sección "Páginas y Cartas" de El Cojo Ilustrado de Caracas (VI, No. 124, 15 de febrero de 1897, p. 177). Posteriormente pude averiguar que la nota recopilada por Zumeta apareció con la firma de Puck, pseudónimo bien conocido de Manuel Gutiérrez Nájera, insertado discretamente a media columna de la sección "Crónica de la semana" de El Universal.

Zumeta empieza su ensayo evocando a Martí y a Gutiérrez Nájera de sobremesa en un restaurant de la ciudad de México a principios del verano de 1894. Dos días después de este encuentro, según nos informa Zumeta, "José Martí salía de la cárcel de Veracruz en donde había entrado a visitar a Díaz Mirón, cuando un amigo puso en sus manos el último número de El Universal de México. El poeta había escrito al separarse de su amigo una página sin firma, pero marcada con el sello de

13 José Martí, Cartas a Manuel A. Mercado. Prólogo de Francisco Monterde. México: Ediciones de la Universidad Nacional Autónoma de México, 1946.

14 Véase el número, "Homenaje a José Marti" de la Revista Cubana, XXIX (1951-1952); Andrés Iduarte, op. cit.

15 José de J. Núñez y Domínguez, Marti en México. Carta Prólogo del Dr. José Manuel Puig Casauranc. México: Imprenta de la Secretaría de Relaciones Exteriores, 1933. Este comentario de M. G. N. que se publicó en una "Crónica de Puck" fue recopilado por E. K. Mapes, en Obras inéditas de Gutiérrez Nájera. Crónicas de Puck. Nueva York: Instituto de las Españas, 1939, pp. 131134. 
espiritual belleza melancólica que constituye el secreto encanto de su prosa y de sus versos. No hizo frases sino que echó al papel lo que no cabía en el pecho. $Y$ la página resultó digna de los dos, escrita como en romántica exageración dijo alguna vez Lamartine, «no con pluma y tinta, sino con sangre del corazón y el dedo del Dios que nos inspira». Así escribió Gutiérrez Nájera este preludio en su canto de cisne".16

A continuación de su comentario, César Zumeta reproduce el texto completo $^{17}$ de la nota de Gutiérrez Nájera sobre Martí, aparecida en $E l$ Universal el 22 de julio de 1894, que consta de unas cuatrocientas palabras.

Martí y Manuel Mercado, hijo mayor de Manuel A. Mercado, firmaron, el dos de agosto de 1894, el Acta de Registro de Nacimiento de Margarita, segunda hija de Gutiérrez Nájera, que había nacido el 10 de junio. Algunos días después, estando de visita en casa de su amigo, Martí se fijó en los ojos verdes de Cecilia, nacida el doce de enero de 1890, y escribió "literalmente al correr de la pluma, sin una sola corrección", 18 el poema "La cuna de Cecilia". Al llegar El Duque Job, retra-

16 La nota de Gutiérrez Nájera se publicó en El Universal. el 22 de julio de 1894. Si dos días después de que los dos poetas se estrecharon "por última vez las diestras", Martí salía "de la cárcel de Veracruz en donde había entrado a visitar a Díaz Mirón", la conversación de sobremesa a que alude Zumeta se habría efectuado hacia el veinte de julio.

Alfonso Herrera Franyutti ofrece varios datos importantes relacionados al último viaje del apóstol a México, en su Martí en México (1969), libro de que no tenía yo conocimiento al escribir la nota "Martí en México: 1894. Un escrito de Puck", publicada en El Libro y El Pueblo (No. 61, febrero de 1970, pp. 9-12).

En la sección de su libro "Cronología de Martí en México en 1894" (pp. 139-140), Herrera Franyutti consigna, entre otros, los datos siguientes sobre el itinerario de Martí: (julio); el 16 embarca en Nueva Orleans hacia México; llega a Veracruz el 18; visita a Mercado y Juan de Dios Peza el 19; el 20 permanece en cama en el Hotel Iturbide; el 21, visita la academia, luego permanece en cama en casa de Mercado; el 25, escribe a Gonzalo de Q. anunciándole que prolonga su viaje. A las 7 P.M. llega a Veracruz; el 26, está en Veracruz; el 27, está en camino de regreso a México; el 28, El Universal informa de su paso por México. Este último dato nos plantea cierto problema. Tengo en mi poder la copia de la página de El Universal en que Gutiérrez Nájera publicó la nota previamente mencionada. La página lleva el membrete: El Universal, Periódico Bicotidiano. México, 22 de julio de 1894. En el caso, si no se trata de un error tipográfico, debe tratarse de la reproducción de dicha nota en el número (que no hemos visto) de El Universal correspondiente al 28 de julio de $18 \% 4$. Conviene notar, sin embargo, que al citar el artículo de El Universal, Herrera Franyutti (p. 125) omite las mismas palabras (en letra bastardilla) que omitió Núñez y Domínguez (p. 82), es decir "Ha pasado por México rápidamente - tal vez a la hora en que estas líneas aparezcan habrá ya partido- un gran artista..."

17 Tanto el texto completo de Zumeta como el comentario de Gutiérrez Nájera, se recopilaron en la nota de Carter, "Martí en México: 1894. Un escrito de Puck", El Libro y El Pueblo (No. 6l, febrero de 1970, pp. 10-12).

18 Margarita Gutiérrez Nájera, Reflejo. Biografía anecdótica de Manuel Gutiérrez Nájera. México: Instituto Nacional de Bellas Artes, 1960, pp. 154-155. 
sado en esta ocasión como lo solía ser para las citas, encontró sobre su escritorio la famosa poesía que empieza con los versos:

En la cuna sin par nació, la airosa niña de honda mirada y paso leve que el padre le tejió de milagrosa música azul y clavellín de nieve

Esta poesía con dedicatoria "A Manuel Gutiérrez Nájera" se publicó en el número 16 de la Revista Azul correspondiente al 19 de agosto. Además de esta composición, se publicaron con su firma en la Revista Azul doce poesías: "Príncipe enano" y "Musa traviesa" de Ismaelillo;19 "Mi caballero"; 20 seis selecciones tomadas de Versos sencillos cuyos primeros versos son: "Viene de gorro y casquete";21 "Para modelo de un dios",22 "Tiene el leopardo un abrigo", "Ayer la vi en el salón", "El enemigo brutal", "El rayo surca, sangriento", "Dolora griera" de Versos varios.23 Con el título de "Versos" aparece allí24 la poesía que empieza, "Oh mi vida que en la cumbre". Además de estas poesías se publicó en la Revista Azul una nota de Martí sobre Antonio Fernández Grilo. ${ }^{25}$

En el Segundo Almanaque Mexicano de Arte y Letras (1896), se publicaron dos páginas de Homenaje ${ }^{26}$ a Martí, en las que aparecen bre-

19 Revista Azul, I, No. 23 (7 de oct., 1894), 359-360; 360-362.

20 Ibid., II, No. 12 (20 de enero, 1895), 183.

21 Ibid., III, No. 23 (6 de oct., 1895), 363.

22 Ibid., V, No. 9 (28 de junio, 1896), 133-134.

23 Ibid., IV, No. 12 (19 de enero, 1896), 185.

24 Ibid., II, No. 22 (31 de marzo, 1895), 353-354. Con respecto a estos "Versos", se añade la nota siguiente en Indice de la Revista Azul por Ana Elena Díaz Alejo y Ernesto Prado Velázquez (México: Universidad Nacional Autónoma de México, 1968, p. 314): "En las Obras completas de José Martí, La Habana; Edit. Lex, 1946, vol. II, pp. 1494-1496, aparecen con el título de "Rimas". La RA incluye la rima VII, que no aparece en las citadas "Rimas", de Obras completas: "¿Ese? / Esta muerto./ ¿Vive?/ Anda vivo./ |Sacúdelo! En verdad que no se mueve:/ La vida sin amor es muerte y nieve./ Un beso./ |Está despierto!/ |Yo te amo!/ ¡Cuán altivo!/ El alma siento palpitar robusta; / IOh, ley de amor generadora y justa!" Con el número XIII [error, por VIII] la RA presenta, sin título, y como continuación de los versos anteriores, el poema que en Obras completas lleva el título de «Juguete».

${ }_{25}$ En 1951 encontré un poema por el mismo Grilo titulado "Tu traje azul" quc apareció en el número de El Siglo XIX correspondiente al 24 de agosto de 1874. No conozco otro poema de aquel tiempo, escrito en español que anticipe con mayor modernidad los procedimientos sintéticos de los modernistas en el uso de simbologías cromáticas. Es posible que tanto Martí, quien habría de llegar a México el 8 de febrero de 1875, como el joven Manuel Gutiérrez Nájera, leyera la composición de Grilo y fueran impresionados por ella. Martí permaneció en México hasta fines de 1876. Para más información sobre Grilo y este poema, véase Boyd G. Carter, En torno a Gutiérrez Nájera y las letras mexicanas del siglo XIX, México: Botas, 1960, pp. 231-232.

26 Manuel Caballero gozaba de cierto prestigio en las letras patrias por el 
ves pensamientos de Manuel Larrañaga Portugal, de Alberto Leduc, de Amado Nervo, de Eduardo E. Zárate, y de Manuel Caballero, con poesías de José López-Portillo y Rojas, de Bartolomé Carbajal y Rosas, de Justo Sierra, y de Juan de Dios Peza. Alberto Leduc afirma que Martí dio la vida por una causa "que a los burgueses egoístas parece absurda!" Opina el mismo autor que si algún día Cuba llega a ser libre no sólo los compatriotas de Martí "sino todos los escritores de la América Latina y todos los que deseen para la humana especie, el mejoramiento social", deberán ir a su sepulcro "en peregrinación piadosa". ${ }^{27}$

Amado Nervo ofrece el testimonio siguiente en la misma sección de homenajes: "Le conocí, nutrí mi espíritu con su verbo radiante y oyendo hablar al patriota, creí en la libertad".28 En otro lugar del Segundo Almanaque Nervo elogia a Martí como héroe, patriota, periodista, conversador, así como por sus "estrechas relaciones intelectuales" con los escritores de México, y por su "perfectísima concepción del arte, profunda erudición y fecundidad notable". 29 . Por último, Nervo templa sus elogios sentando juicios más bien peyorativos sobre Martí como poeta y escritor. Dice que en vez de ser "un adorador de la forma métrica" es tal forma en Martí "desaliñada, frecuentemente exótica y. aun extravagante. Sus procedimientos literarios son poco armónicos y aun se distinguen a veces, por su incoherencia, pero bajo tal desordenado atavío, adivinábase siempre una inspiración poderosa que, bien encauzada, hubiera hecho admirar su hermosura y embelesos". ${ }^{30}$

¿Sería también de la pluma de Nervo — según supone Núñez y Dominguez-3. el editorial sobre la muerte de Martí que se publicó en El

éxito de sus Almanaques, el primero en 1882, el segundo en 1895 , y el que nos ocupa, en 1896. En 1907 tuvo este señor la rara ocurrencia de desenterrar la Revista Azul con el propósito nada menos que de combatir el Modernismo. Don Francisco González Guerrero dedica un estudio interesantísimo a la resurrección fallida de la Revista Azul ("empresa bastarda" la llama Alfonso Reyes) en el número 13 de la Revista Metáfora. Manuel Gutiérrez Nájera escribió la sección "Revista artística" del Almanaque Mexicano de Arte y Letras aparecido en 1895. El índice del contenido fue reproducido en la Revista Azul (IV, No. 9, 29 de diciembre de 1895, p. 144). Además de los homenajes a Martí en las páginas 94-95 del Segundo Almanaque, en la misma revista (p. 107) se halla una poesía dedicada a Martí por Enrique Pérez Valencia.

27 Segundo Almanaque Mexicano de Arte y Letras, 1896, p. 94.

28 Ibid., p. 95.

29 Amado Nervo escribió la "Sección Literaria" del Segundo Almanaque Mexicano de Arte y Letras, 1896, pp. 23-32. Se trata de Martí en la página 28. 30 Ibid.

${ }^{31}$ José de Jesús Núñez y Dominguez, op, cit., p. 188. Véase también Andrés Iduarte, Martí escritor. México: Ediciones Cuadernos Americanos, 1945, 360361 . 
Mundo ${ }^{32}$ con fecha dos de junio de 1895 ? He aquí la nota necrológica en cuestión:

\section{José Martí}

Se ha plenamente confirmado la muerte del conocido insurgente cubano. Murió en un encuentro de armas, luchando por la idea a que consagró su existencia y reposo. Era un espiritu lleno de llamas, inquieto y vibrante. Alucinado febril, su recuerdo merece respeto.

No hace muchos meses llegó a esta capital. Hablaba rápidamente, como un hombre que tiene prisa en irse. Se desbordaba en torrentes de elocuencia alocada y pintoresca, rica como la exúbera naturaleza de su patria.

Corría de república á república y de pueblo á pueblo, sembrando con su voz la fe ardorosa de la idea que lo agitaba, enardeciendo ánimos adormidos, azotando voluntades yacentes.

A través de la incoherencia de sus discursos, se sentía palpitar una fe profunda, algo como un misticismo vago.

Fué durante muchos años el alma de la rebelión de Cuba: formaba comités, juntas revolucionarias, reclutaba esfuerzos, incansable, resuelto, ora doliente como la sombra de un dolor trágico y solemne, ya altivo y osado como el paladín medioeval de una cruzada santa.

Escribió estrofas desordenadas, caóticas, hijas de su neurotismo agudo; desbordó prosa incisiva, sin método, atropellada, hervorosa; lamentos de Isaías, gritos del Luzbel de Milton, naderías donaidosas, puñados de flores, fulguraciones de armas... todo revuelto, palpitante, muy aprisa, muy aprisa como en la balada del poeta.

Expresivo, vehemente, red de nervios sacudida sin descanso por el soplo de una alta misión, ejercía un singular encanto en las personas que se le acercaban.

Su muerte es un motivo de duelo para la joven América.

No juzgamos la razón y la justicia de su causa.

Vivo, era el sublime enamorado de una idea: muerto, es un vencido a quien se respeta.

32 El Mundo, I, No. 22 (2 de junio, 1895), p. 7. 
$\mathrm{Si}$ es cierto que esta nota of rece elementos de parentesco con el comentario ambiguo publicado por Nervo en el Segundo Almanaque Mexicano de Arte y Letras, no lo es menos que la dirección de El Mundo, a juzgar por los artículos y editoriales dedicados al asunto a partir del 24 de marzo de 1895, no demuestra entusiasmo por la causa de la Independencia de Cuba. En la mayor parte de estos artículos ${ }^{33}$ y notas hay referencias a Martí y a su actuación como presidente del partido revolucionario cubano. Por esto, nos parece injusto atribuir exclusivamente a Nervo la paternidad de un escrito que refleja las opiniones de la dirección de El Mundo. Además, no concretamente Nervo sino también algún otto colaborador de El Mundo pudo haber sido el autor de dicho comentario. Comparto la opinión ${ }^{34}$ de Andrés Iduarte de que José de Jesús Núñez y Domínguez debe estar equivocado al atribuir a Nervo la paternidad de $\tan$ falsas apreciaciones sobre Martí escritor, envueltas como lo están, en concesiones de doble sentido ante el sacrificio del poeta y héroe de Dos Ríos.

Dado el gran prestigio ${ }^{55}$ de Martí en Venezuela a partir de su presencia allí en 1881, sorprende que la tragedia de Dos Ríos no mereciera sino una simple nota en El Cojo Ilustrado. Para Pedro María Brito Gon-

33 En el artículo titulado "Las revoluciones en Cuba" (El Mundo, 24 de marzo de 1895 , p. 7), se refiere a Martí como jefe del partido revolucionario, así como a sus esfuerzos por invadir Cuba. Hay otro ensayo sobre "Las revoluciones en Cuba" en $E l$ Mundo del 31 de marzo de 1895, p. 5. En el número del 21 de abril de 1895 se refieren los antecedentes históricos de la lucha revolucionaria cubana, junto con fotografías de los líderes, inclusive la de Martí a quien se designa como jefe del partido separatista cubano. La nota sobre la muerte del héroe aparece en El Mundo de 2 de junio de 1895 . En octubre de 1895 se dice en un editorial de "el verdadero patriotismo cubano consiste en reconocer la necesidad que todavía tiene Cuba de vivir bajo el régimen colonial, y pedir por medios pacíficos la libertad compatible con su estado social, bajo la tutela de la metrópoli" (El Mundo, II, No. 16, 27 de octubre de 1895, p. 9). En mayo de 1896 el autor de "Notas editoriales" examina el propósito de «Los señores del 'Comité organizador' de 'Cuba Mexicana'», un grupo de personas bien conocidas en el mundo de la política, en el del periodismo, el comercio y las profesiones, nacionales unas, extranjeras las otras". El Mundo rechaza tal idea. "La unión de Cuba al territorio mexicano la encontramos perjudicial para la Isla y para la República" (El Mundo, I, No. 19, 10 de mayo de 1896, p. 282).

${ }^{34}$ Con respecto a Nervo y la nota en El Mundo, Iduarte dice: "En El Mundo, que después fue El Mundo Ilustrado, encuentra Núñez y Domínguez unas letras que supone de Nervo, suposición que no queremos compartir. Se escribieron como comentario a su muerte: «No juzgamos la razón y la justicia de su causa», dice alguien que ojalá no haya sido Nervo. Lo demás, son, naturalmente, amargas apreciaciones envueltas en concesiones ante la muerte". $\mathrm{Op}$. cit., p. 361.

35 Véase: Gonzalo Picón-Febres, La literatura venezolana en el siglo XIX, cap. IV, pp. 153-158 (recopilado en la Revista Cubana, XIX, julio 1951-diciembre 1952, pp. 167-169). Buenos Airęs: Editorial Ayacucho, 1947. 
zález, autor del comentario aparecido en el número de El Cojo ${ }^{36}$ correspondiente al primero de enero de 1896, "El nombre de Martí, quizás el más puro de los que registrará la Historia en sus anales es una gloria de la Humanidad". Hay que recordar que a este mismo escritor, compañero de aulas de Picón-Febres, debemos una valiosa impresión de Martí como orador en $E l$ Club del Comercio de Caracas. ${ }^{37}$ En otro lugar. de este estudio se ha aludido a la nota de César Zumeta sobre Martí y Gutiérrez Nájera, en $E l$ Cojo Ilustrado. ${ }^{38}$

La revista Cosmópolis (1894-1895) de Caracas le dedicó a Martí el artículo de fondo de su último número, el 12, correspondiente al mes de julio de 1895. El dominicano, José Ramón López, autor del comentario, le rinde sincero homenaje, evocando con emoción la labor extraordinario del Apóstol, que "inquicto, iluminado, sublime, predicaba en la cárcel, al aire libre, donde quiera que estuviese inflamando con su entusiasmo los corazones en todos los países que recorrió como peregrino de la redención del suyo... Un hombre sólo, un poeta débil de cuerpo, recogió dentro de sí toda el alma de la patria". ${ }^{39}$

En ninguna de las revistas examinadas para la redacción de este trabajo, ni antes ni después de su muerte, se calificó a Martí de modernista. Las dos citas que siguen sirven para ilustrar hasta qué punto se solía hacer caso omiso del nombre de Martí al pasar lista a los jefes y soldados rasos del Modernismo. En Cosmópolis se afirma que "Rubén Darío, Gutiérrez Nájera, Gómez Carrillo, Juliản del Casal y tantos otros dan vida a nuestra habla castellana. .."40 En El Iris se asevera que Salvador Rueda "pertenece a la legión modernista de que él es pontífice en España y Rubén Darío en América, y en que descuellan personalidades tan brillantes como las de Gómez Carrillo, Soto Hall, Facio, Gavidia, Gutiérrez Nájera, Arciniegas y Casal, el malogrado poeta de la musa triste". ${ }^{41}$

Al parecer, al colombiano-panameño, Darío Herrera le cupo la distinción de ser el primero que determinó y afirmó la importancia de Martí en el desarrollo del Modernismo, aun cuando es cierto que Gutiérrez Nájera, Dario y otros escritores le tenian por modernista sin

$36 \mathrm{El}$ Cojo Ilustrado, V, No. 97, 1o. de enero de 1896, p. 22.

37 Véase: Gonzalo Picón-Febres, op. cit.

38 Véase: César Zumeta, "Un 'suelto' de crónica", El Cojo Ilustrado, VI, No. 124 (15 de febrero de 1897), p. 177.

39 José Ramón López, "José Martí", Cosmópolis, Año II, No. 12 (julio de 1895), pp. 98-101. Al final del artículo se dice "Caracas: julio de 1895".

10 Pedro Emilio Coll en "Charloteo", Cosmópolis, I, No. 1 (10. de mayo de 1894$)$, p. 4.

41 Enrique A. Carrillo, "Salvador Rueda", El Iris, No. 2 (lo. de julio de 1894), p. 47. 
emplear esta palabra para definir su talento. En su artículo ${ }^{42}$ de intento tan reivindicador como justiciero, titulado "Martí, iniciador del modernismo" que se publicó en el número de julio de 1895 de la revista Letras y Ciencias de Santo Domingo, Herrera se refiere a un folleto de Clemente Palma - que no he leído- en que el hijo de don Ricardo nombra como iniciadores del modernismo a Darío y a Casal. Herrera disiente de esta opinión. Dice: "Para mí Darío y Casal han sido los propagadores del modernismo, pero no los iniciadores. Este título corresponde más propiamente a José Martí -olvidado por Palma en las citas que hace de los modernistas americanos- y a Manuel Gutiérrez Nájera. Ambos vinieron a la vida literaria mucho antes que Darío y Casal, y eran modernistas cuando todavía no había escrito Darío su $\mathrm{Azul}$ ...ni Casal su Nieve". ${ }^{43}$

El nombre de Francisco Mostajo, peruano, se encuentra raramente en los índices onomásticos aun cuando sus composiciones aparecieron en revistas de la valía de la Revista Cómica de Chile y de la Revista Nacional de Literatura y Ciencias Sociales de Montevideo. No obstante su relativa obscuridad como escritor, Mostajo merece un párrafo en la his. toria del modernismo por su disertación titulada $\mathrm{El}$ Modemismo $i$ el Americanismo, presentada en la Universidad de Arequipa, en 1896, paso optar el Bachillerato en la Facultad de Filosofía y Letras. En opinión de Mostajo "Martí, el heroico vástago revolucionario de Cuba i Gutiérrez Nájera, el cincelador aristocrático de México, han sido en América los primeros exploradores del bosque virgen del Modernismo. Por la trocha abierta por ellos se ha precipitado después como bandada de pájaros en desorden, la entusiasta bohemia loca" ${ }^{45}$

42 Dario Herrera, "Martí, iniciador del Modernismo", Letras y Ciencias (Santo Domingo), No. 97 (julio de 1895). Reproducido en la Revista Dominicana de Cultura, No. 2 (1955), p. 255.

43 Citamos de "En torno a la iniciación del modernismo" por Manuel Pedro González en Estudios críticos sobre el Modernismo por Homero Castillo. Madrid: Editorial Gredos, S. A., 1968, p. 237. Véase también Iván A. Schulman, Génesis del Modernismo. St. Louis (USA) y México D. F.: El Colegio de México y Washington University Press, 1966, pp. 11-12.

44 Véase: John M. Fein, Modernismo in Chilean Literature, pp. 135-147 para el Indice de la Revista Cómica (1895-1898).

45 Francisco Mostajo, El Modernismo y el Americanismo. Arequipa: Imprenta de "La Revista del Sur", 1896, pp. 4-5. Al final de la disertación se pone la fecha mayo 12 de 1896.

En la sección "Notas bibliográficas" de la Revista Nacional de Letras y Ciencias Sociales (III, No. 54, 25 de agosto de 1897, p. 95) se acusa recibo de esta obra en estos términos: "El señor Francisco Mostajo, escritor y poeta de la nueva generación peruana, cuyos fáciles y elegantes versos han lucido en las páginas de las mejores publicaciones literarias del continente, nos favorece con un ejemplar del opúsculo en que ha editado su disertación relativa a $E l$ 
Como conclusión, ofrezco el soneto, tan profético como bello, que compuso Justo Sierra, al saber de la muerte del héroe:

\section{José MaRtí}

No ocultará por siempre a nuestra vista tu cuerpo sacro el arenal nativo iay! sin que mi lamento fugitivo diga el dolor que al corazón contrista.

De una patria empeñado en la conquista, por tu heroico ideal moriste altivo... ¿Quién pudiera volvernos redivivo al gran poeta, al soberano artista!

En la lira de Ámérica pondremos tu cadáver, así lo llevaremos en nuestros propios hombros a la Historia;

En la paz de tu noche funeraria, acaso, como lámpara de gloria, brille, un día tu estrella solitaria. ${ }^{46}$

\section{University of Missouri}

Boyd G. Carter

Modernismo y el Americanismo, en cuanto tendencias literarias, leído ha poco tiempo en la Universidad de Arequipa". En el comentario que se hace de la obra, se menciona a Gutiérrez Nájera pero no a Martí. Con respecto a esto, conviene recordar que el artículo de Luis Berisso, "Manuel Gutiérrez Nájera", apareció en el número de Revista Nacional de Literatura y Ciencias Sociales correspondiente al diez de junio de 1897. Con anterioridad Paul Groussac lo había publicado en La Biblioteca (IV, abril-junio de 1897). Dicha referencia a la obra de Mostajo es importante en el sentido de que informa que los redactores, por lo menos, tuvieron la oportunidad de leer lo que dice el autor del opúsculo sobre el papel de Gutiérrez Nájera y de Martí como iniciadores del Modernismo. De Mostajo se publicaron en la Revista Nacional un artículo sobre Manuel B. Ugarte (III, No. 59, 10 de noviembre de 1897, pp. 170-171) y el poema "Rápidas" en el mismo número (p. 174).

En Epistolario de Rubén Darío con escritores peruanos, publicado por Willy Pinto Gamboa en 1967 (Lima: Universidad Nacional Mayor de San Marcos, y Universidad de Chile, 1967) se halla una carta de Francisco Mostajo a Rubén Darío, pp. 43-44).

${ }^{46}$ Recopilado de la Revista Cubana XXIX (jul,, 1951-dic., 1952), p. 119. 